\title{
THE EFFECT OF QUANTITATIVE REDUCTION OF RENAL BLOOD FLOW UPON THE PREGNANT RABBIT
}

\author{
By L. V. DILL, C. E. ISENHOUR, AND J. F. CADDEN \\ (From the Department of Obstetrics and Gynecology, Cornell University Medical College, and \\ the New York Hospital, New York City)
}

(Received for publication July 27, 1939)

In a recent paper (1) we described a syndrome which occurred in pregnant dogs and rabbits subjected to renal ischemia and which was characterized by hypertension, albuminuria, coma, convulsions, and death. In most of the animals uremia and hematuria were also noted, but these were not constant findings. Cardiac dilatation with acute congestion of all organs, and necroses in the liver, myocardium, and kidneys were the usual findings at autopsy.

Bilateral constriction of the renal arteries rendered estimation of the actual renal flow so difficult that only very gross variations could be appreciated, and varying amounts of renal damage and nitrogen retention complicated the picture. A more precise quantitative method was needed in order to subject the animals to comparable amounts of renal ischemia.

Rytand (2) described the production of renal ischemia by reducing the blood flow through the aorta proximal to the points of origin of the renal arteries. It seemed that the utilization of this method with the application of a clamp of known diameter to the previously measured aorta should give a fairly accurate estimation of the relative reduction of blood flow through the kidneys.

\section{METHOD}

Six pregnant and eight non-pregnant female rabbits of 8 pounds or more in weight and of varying breeds were used as the experimental animals in which to constrict the aorta proximal to the points of origin of the renal vessels and four pregnant animals of the same type were used to control the effect of simple aortic constriction by placing the clamp distal to the points of origin of these arteries. These animals were obtained from a local dealer and were observed for three weeks before the experiment was begun.

For an additional period of three weeks blood pressure was recorded three times weekly by an indirect method (3).

Urine was collected in metabolism cages and examined weekly. Specific gravity was determined by a calibrated urinometer; albumin was tested qualitatively by the heat and acetic acid test, and careful microscopic examinations were done on the urine after it had been centrifuged at low speed.

Measurements of the cell volume, red blood cells, and hemoglobin were done weekly. Studies of the cell volume were done by the Wintrobe (4) method; the red blood cells were counted in chambers, using pipettes approved by the Bureau of Standards; and hemoglobin estimations were made by the Sahli technic.

Chemical measurements of the blood were made at weekly intervals. Measurements of the non-protein nitrogen were done by the method of Folin and Wu (5); of urea by the method of Van Slyke and Cullen (6) ; and of uric acid by the Folin (7) technic. Cholesterol was determined by the method of Leiboff (8), chlorides by the Whitehorn (9) method, and the carbon dioxide combining power by the method of Van Slyke (10).

Following the period of three weeks during which control studies were made the animals were subjected to laparotomy under aseptic technic. The aorta, which had been measured at laparotomy, was constricted above or below the points of origin of the renal arteries to varying degrees by means of a silver wire loop, the inside diameter of which had been measured before application. The aorta of each animal with aortic constriction proximal to the points of origin of the renal vessels was also constricted to an equivalent degree distal to the points of origin of the renal arteries to prevent the return of any appreciable amount of blood to the kidneys upon development of a collateral circulation.

The non-pregnant control animals in which the aortae were constricted proximally and distally to the origin of the renal arteries were divided into four groups of two animals each. The cross-sectional areas of the aortae of these animals were constricted to approximately one-sixth, one-fourth, one-half, and two-thirds of the original value.

The pregnant experimental animals were divided similarly into three groups of two animals each and the cross-sectional areas of the aortae proximal and distal to the origins of the renal arteries were constricted to one-fourth, one-half, and two-thirds of the original measurement. The aortae of this group were not constricted to one-sixth of the original cross-sectional area since it was felt that pregnant animals subjected to such renal injury would not survive long enough to be of value. The aorta was constricted when the animal was in the last half, or in some instances the last third, of the period of gestation. 
The pregnant control animals in which the aorta was constricted only distally to the origins of the renal arteries were divided into two groups of two animals each. The aorta was reduced to approximately onesixth and one-fourth of the original cross-sectional area.

Following constriction of the aorta, blood pressure determinations were made daily; examination of the urine, chemical measurements of the blood, and hematologic studies were done usually every other day until death occurred. If it seemed obvious that the animal would survive indefinitely, such studies were made for a period of twelve to fifteen days and from then on at frequent intervals. Following delivery of a pregnant animal the studies were made on the same plan until a stationary level was reached.

Each animal was autopsied within four hours after death, and numerous sections of all viscera, glands of internal secretion, brain, and bone marrow were taken.

\section{RESULTS}

No data are presented on those pregnant animals in which constriction of the aorta was carried out only distally to the points of origin of the renal arteries. Both preceding and following operation, blood pressure values ranged from 80 $120 \mathrm{~mm}$. $\mathrm{Hg}$, urine studies showed no evidence of abnormalities (albumin or casts), and the blood chemistry measurements were within normal limits. All of these animals delivered living term fetuses. Likewise no data are presented on those of the non-pregnant animals in which the crosssectional area of the aorta proximal and distal to the renal arteries was reduced to one-sixth of the original value. Both animals died within eighteen hours following operation, and no blood pressure or urine studies were carried out. Chemical studies on the blood obtained at postmortem examination showed evidence of nitrogen retention only. Autopsy demonstrated cardiac dilatation, pulmonary edema, and areas of hemorrhage and necrosis in the adrenal glands and kidney cortices. In view of the short periods of survival following operation, it seemed worthless to evaluate such severe constriction, and the data on these animals are not included in the tables.

The data on all animals in which constriction of the aorta had reduced the cross-sectional area to one-fourth of the original value are presented in Table I. The blood pressure in both nonpregnant animals sustained a moderate elevation during the entire length of the period of postoperative observation, but in the pregnant animals no significant rise in tension was noted until the pregnancy had terminated, following which the course was identical with that of the non-pregnant animal. In both non-pregnant animals a slight transient rise in blood non-protein nitrogen and urea occurred after aortic constriction. No change was noted in the pregnant animal in which resorption of the fetuses had taken place. In the other pregnant animal the non-protein nitrogen and urea became elevated following aortic constriction, but rapidly returned to normal after delivery. Both the non-pregnant and pregnant animals showed a moderate decrease in uric acid levels, particularly noticeable in Animal B in which the uric acid values were depressed despite the marked elevation of other nitrogenous products. In both groups of animals the hemoglobin, red blood cell and cell volume values markedly decreased immediately after laparotomy and then returned toward normal. The urine of the nonpregnant animals contained a trace of albumin and an occasional hyaline or granular cast. Aortic constriction in the pregnant animal was followed by the gradual onset of severe albuminuria and gross hematuria with a complete remission of both following the termination of pregnancy.

Table II shows the effect of reducing the crosssectional area of the aorta to approximately onehalf of its original value. Both of the non-pregnant animals developed a moderate hypertension which was noticeably less marked in degree and rapidity of onset than that seen in the more severely constricted group. Here again no definite rise in the blood pressure was noted in the pregnant animal until delivery had occurred. No significant changes in the blood non-protein nitrogen or urea were noted in either of the non-pregnant animals, nor in one of the animals of the pregnant group. The other pregnant animal showed a marked elevation of these substances following the production of renal ischemia with an immediate return to normal following delivery. No significant change in the uric acid level was noted in any animal of this group, although Animal B showed no elevation of uric acid despite marked retention of the other nitrogenous products. The usual decrease in hemoglobin, red blood cell and cell volume values was noted following laparotomy in all animals except Animal B, in which an equivalent amount of blood evidently was lost 


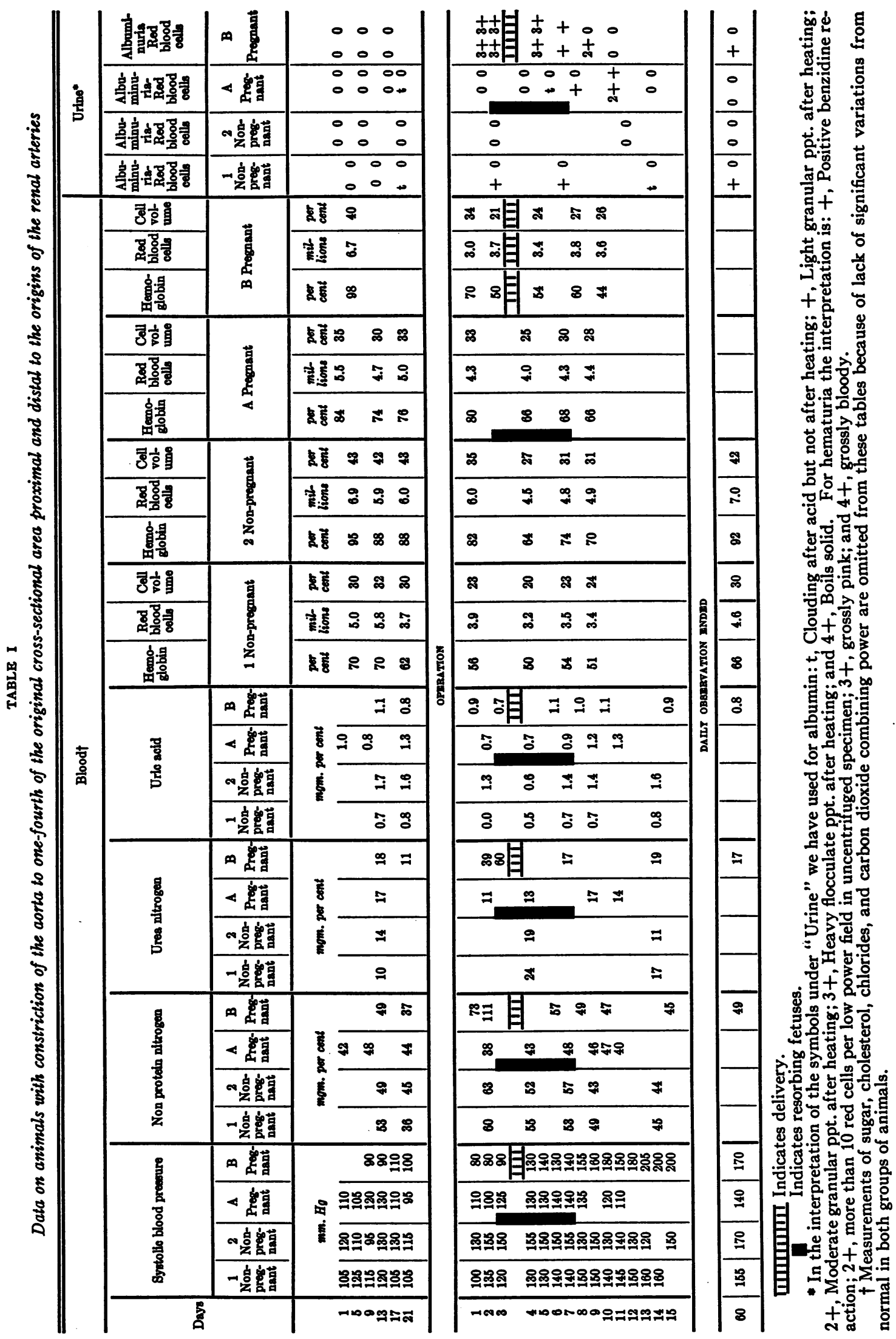




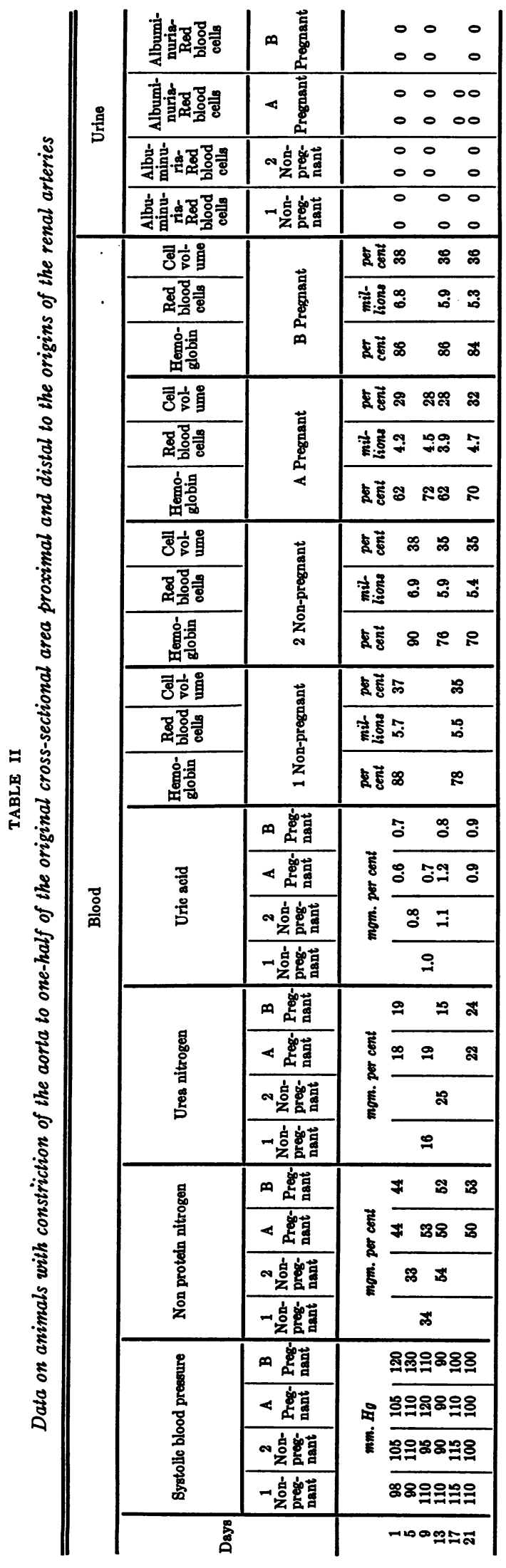

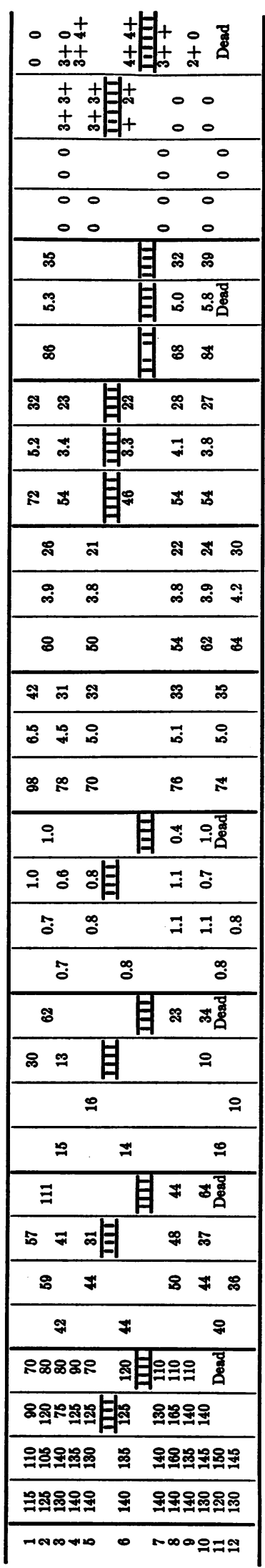

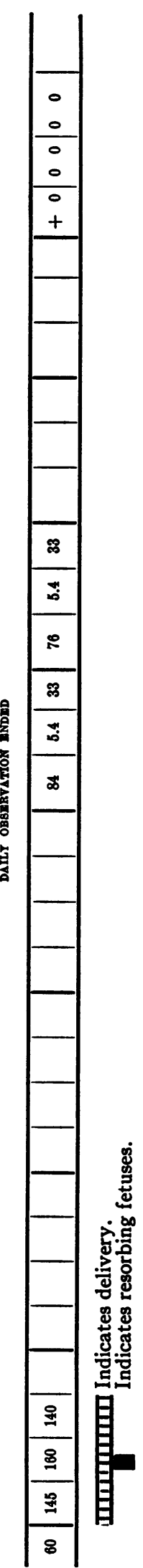


during the operation. The urinary constituents of the non-pregnant group were not altered, while both of the pregnant animals developed albuminuria and hematuria to a marked degree preceding delivery. A complete remission was noted in one animal following expulsion of the fetuses, while in the other, although the hematuria cleared up completely and the albumin was markedly reduced, a moderate amount of albumin persisted until death occurred.

The autopsy findings on the pregnant animal of the moderately constricted group in which death occurred four days following delivery were: healing abdominal wound; striate areas of necrosis in the cortices of both kidneys; gangrene of terminal ileum; fibrino-purulent peritonitis; lobular pneumonia of the right lower lobe; cloudy swelling of the liver, spleen, and heart; cardiac dilatation; and acute pulmonary edema. It was felt that recovery of the animal was imminent when infarction of the intestine occurred, and that the terminal rise in blood nitrogen as well as the albuminuria and death were directly attributable to this accident.

The effect of constricting the aorta to twothirds of its original cross-sectional area is shown in Table III. In both of the non-pregnant and in one of the pregnant animals of this group there was at most a slight elevation of blood pressure. In the remaining pregnant animal, however, a marked rise occurred immediately following aortic constriction and persisted until one day before death. In neither of the gravid animals was there a significant change in non-protein nitrogen or urea although in Animal A a slight decrease in uric acid occurred. Hemoglobin, red blood cell and cell volume values, particularly in the nonpregnant animals, showed a less marked decrease than occurred in the more severely constricted group. Albuminuria was noted only in the pregnant animals, and delivery in Animal A caused the urine to become completely negative.

Autopsy findings on the pregnant animal of the minimally constricted group, which died while resorbing the fetuses, were: cloudy swelling of the kidneys; focal necrosis of the liver and myocardium; cardiac dilatation; infarction of the spleen; infected pulmonary infarct of the right lower lobe with extension to the diaphragm; corpora lutea of the ovaries; and retained placental tissue. We believe that death and pathologic findings in this animal are directly attributable to the syndrome produced by renal ischemia in the pregnant animal.

\section{DISCUSSION}

The differences in the clinical courses of these animals were quite apparent. At no time following operation did any of the non-pregnant animals appear ill while, without exception, the condition of the pregnant animals became steadily worse. With the advent of delivery the animal at once became much more lively, the fur immediately regained its glossy appearance, and within two days the animal was apparently normal. The degree of aortic constriction seemed to bear no direct relation to the appearance of the animal.

From these findings it seems logical to believe that the aorta of the non-pregnant animal can safely be reduced to at least one-fourth of its original cross-sectional area without producing more than a persistent hypertension in the nonpregnant female rabbit; yet a reduction to even two-thirds of the original cross-sectional area may produce signs of toxemia and even death in the pregnant animal. That this toxic effect is due to reduction in renal flow and not to mere mechanical blockage is shown by the failure to produce significant changes in the course of pregnancy in animals in which aortic constriction is carried out below the points of origin of the renal arteries. Rytand (11) has shown that the blood pressure elevation which accompanies partial aortic obstruction does not occur when the obstruction is carried out below living kidney tissue and Brotchner (12) has demonstrated that the removal of a large portion of the capillary bed as represented by the kidney causes no significant rise in pressure in animals in which the aorta is constricted at a point below the origins of the renal vessels.

We are unable to explain why the pregnant animal with severe restriction of renal blood flow fails to develop hypertension. Arterial spasm, which is usually considered the promulgator of hypertension, is obviously not decreased in the pregnant animal, but rather increased in a generalized fashion as evidenced by the widespread necroses in the heart, spleen, liver, and kidney of these animals, whereas in the non-pregnant animal 


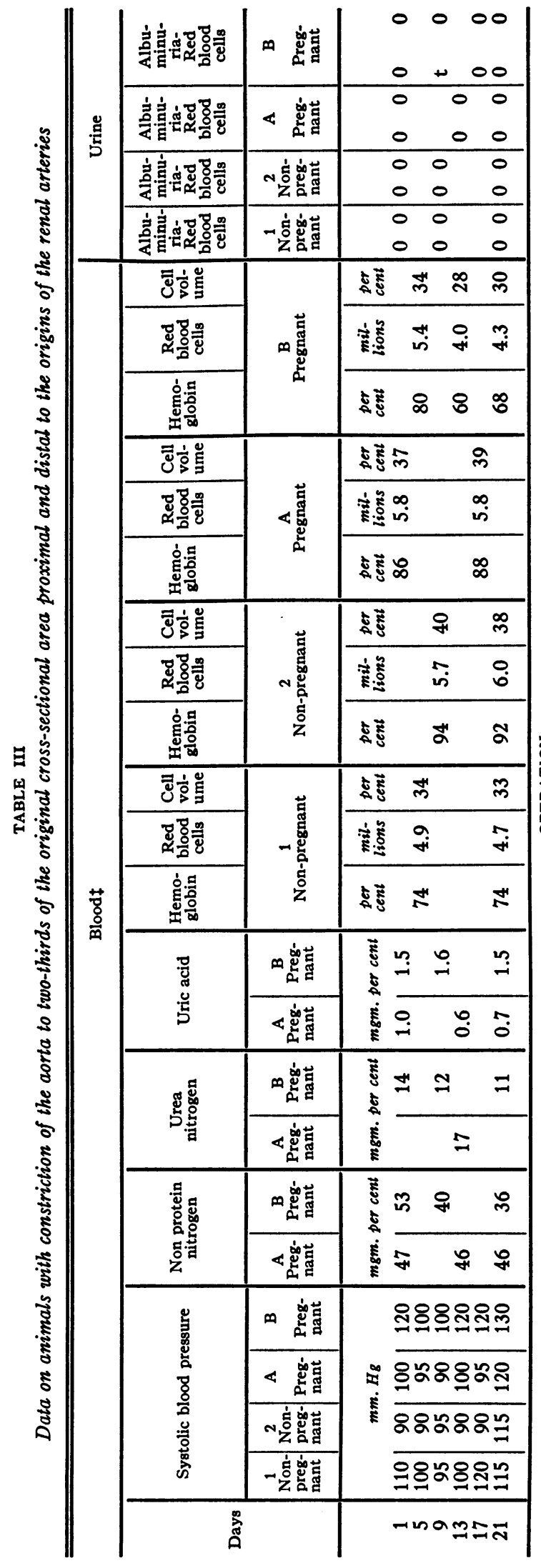

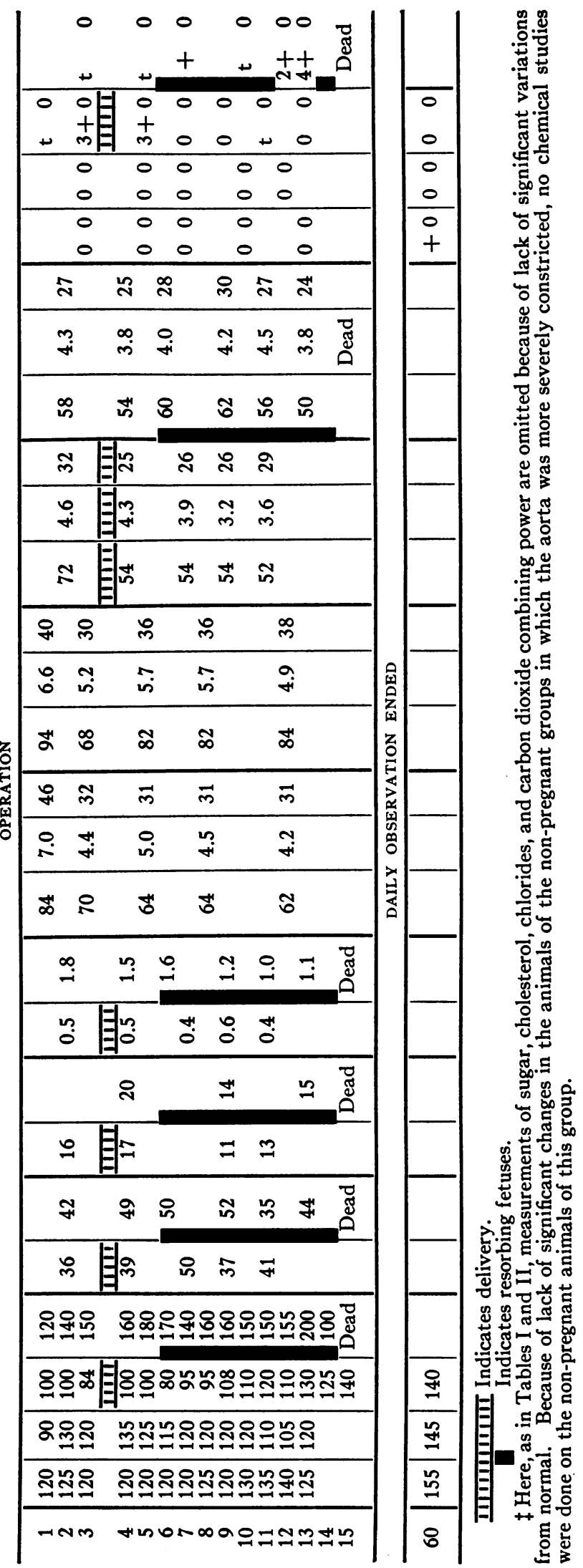


severe hypertension develops without producing any pathologic changes in these organs.

That pregnancy produces this difference in reaction seems obvious from the observations that delivery, or in some cases even the death of the fetuses, seems to effect an immediate recovery, and that thereafter the animal responds as one of the non-pregnant animals in which the aorta has been similarly constricted.

It is noticeable, but perhaps not remarkable, that abortion is much more frequent in these animals than in those animals previously reported (3) in which bilateral renal artery constriction and not aortic constriction was used to reduce the blood supply to the kidney. It is probable that the aortic constriction, by further reducing the blood supply to the uterus as well as to the functioning lutein tissue, plays an important part in this tendency of the uterus to evacuate, especially since these organs as well as the fetuses are probably suffering from a rather marked anemia produced by the arterial spasm associated with this syndrome.

Hemoconcentration such as has been described in the human with toxemia of pregnancy (13, 14) is not noted in these animals, although it is probable that if it occurs it has been masked by operation and by the frequent taking of blood samples.

\section{CONCLUSIONS}

A quantitative method for producing a relative reduction of blood flow through the kidneys is described.

The presence of pregnancy definitely increases the susceptibility of the rabbit to renal ischemia.

Minimal reduction of the blood flow to the kidney of the pregnant animal produces a clinical and pathologic syndrome which closely simulates "toxemia of pregnancy" in the human.

The authors wish to express appreciation to Dr. J. B. Pastore for valuable suggestions in the preparation of this report and for hematologic studies and to Dr. H. F. Traut for aid in the preparation and study of the autopsy material.

\section{BIBLIOGRAPHY}

1. Dill, L. V., and Erickson, C. C., Eclampsia-like syndrome occurring in pregnant dogs and rabbits following renal artery constriction. Proc. Soc. Exp. Biol. and Med., 1938, 39, 362.

2. Rytand, D. A., Pathogenesis of arterial hypertension in coarctation of aorta. Proc. Soc. Exp. Biol. and Med., 1938, 38, 10.

3. Dill, L. V., Erickson, C. C., and Isenhour, C. E., Observations on the effect of renal ischemia on the rabbit in various stages of the reproductive cycle (In press).

4. Wintrobe, M. M., Macroscopic examination of blood. Discussion of its value and description of use of single instrument for determination of sedimentation rate, volume of packed red cells, leucocytes and platelets, and of icterus index. Am. J. M. Sc., 1933, 185, 58.

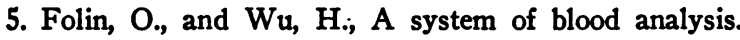
J. Biol. Chem., 1919, 38, 81.

6. Van Slyke, D. D., and Cullen, G. E., A permanent preparation of urease and its use in the determination of urea. J. Biol. Chem., 1914, 19, 211.

7. Folin, O., Improved method for determination of uric acid in blood. J. Biol. Chem., 1930, 86, 179.

8. Leiboff, S. L., Improved apparatus for determination of cholesterol. J. Lab. and Clin. Med., 1925, 10, 857.

9. Whitehorn, J. C., System of blood analysis. Supplement II. Simplified method for determination of chlorides in blood or plasma. J. Biol. Chem., 1921, 45, 449.

10. Van Slyke, D. D., Studies of acidosis. II. Method for determination of carbon dioxide and carbonates in solution. J. Biol. Chem., 1917, 30, 347.

11. Rytand, D. A., Renal factor in arterial hypertension with coarctation of aorta. J. Clin. Invest., 1938, 17, 391.

12. Brotchner, R. J., Hypertension from obstruction of aorta. Proc. Soc. Exp. Biol. and Med., 1939, 40, 264.

13. Dieckmann, W. J., Comparative studies of the blood in the non-convulsive toxemias of pregnancy. Am. J. Obs. and Gyn., 1933, 26, 543.

14. Pastore, J. B., The cell volume following delivery and its relation to blood loss and post-partem infection. Am. J. Obs. and Gyn., 1936, 32, 859. 